\title{
Effectiveness Of Structured Teaching Programme On Knowledge Regarding Menopausal Symptoms And Its Management Among Women
}

\author{
Vruti Patel $^{1}$, Sijo Koshy ${ }^{2}$, Ravindra H.N ${ }^{3}$ \\ ${ }^{1}$ MSc Nursing Student, Sumandeep Nursing College, Sumandeep Vidyapeeth, Piparia, Vadodara-391760, \\ Gujarat, India, \\ ${ }^{2}$ Assisstant Professor, Department Of Obstetrics \& Gynaecology Nursing, Sumandeep Nursing College, \\ Sumandeep Vidyapeeth, Piparia, Vadodara-391760, Gujarat, India, \\ ${ }^{3}$ Principal, Sumandeep Nursing College, Sumandeep Vidyapeeth, Piparia, Vadodara-391760, Gujarat, India
}

\section{Abstract}

Introduction: Menopause is a unique stage of female reproductive life cycle, a transition from reproductive to non-reproductive stage. It is characterized by cessation of menstruation and women may view menopause as a transition from middle age to old age. Some women may look upon this with pleasant anticipation while others have fear during this period because of the anticipated losses.

Objective: The study aimed at assessing the existing knowledge regarding Menopausal symptoms and its management among women, determining the effectiveness of structure teaching programme on Menopausal symptoms and its management among women and finding the association between post-test knowledge scores and selected demographic variable like age, education, occupation.and family type.

Method: A one group pre-test post-test pre-experimental approach was adopted. The study was conducted among 60 menopausal women conveniently selected from two villages of Vadodara. The content validity of the tool and teaching plan was established. Reliability of the tool was tested by split half technique.

Result: It was found that the effectiveness of structured teaching programme in terms of increase in knowledge score among menopausal women was $46.13 \%$.

Conclusion: There is a significant increase in the knowledge of women regarding menopausal symptoms and its management. The structured teachingprogramme was found to be an effective strategy to increase the knowledge of women regarding menopausal symptoms and its management.

Keywords: Knowledge, STP, Menopause, Menopausal symptoms and its management, Menopausal women.

\section{INTRODUCTION}

Menopause is a unique stage of female reproductive life cycle, a transition from reproductive to nonreproductive stage. It is characterized by cessation of menstruation and women may view menopause as a transition from middle age to old age. Some women may look upon this with pleasant anticipation as time of relative freedom from such worries as undesired pregnancies and the stress of child bearing. Many women may have fear during this period because of the anticipated losses. Thus women may be hesitant and ignore the unusual and hormonally related symptoms may go undetected resulting in a delay in diagnosis and treatment. ${ }^{1}$

This transition will be smooth only if women are aware of the natural changes occurring during which will help them to adopt self help behavior and to improve their physical and mental health implies loss of child bearing, capacity and aging. Many women become adjusted to the menopausal symptoms over time by learning to live with them; however some women require intervention for symptom relief, especially if associated with moderate to severe distress of discomfort as menopausal symptoms become more dominant in their life. ${ }^{2}$

Menopause raises important health care issues and present physical challenges. Menopause causes short term changes and there are long term risks that can have a major impact on overall health and quality of life. Some consider menopause to be a call to action, it is a time to learn more about one's body, a process that can be invigorating and empowering. ${ }^{3}$

Several psychological factors are related to the process of physical change. A woman may experience fear of losing her appearance, uncertainty about her purpose in life as a middle-aged woman, sadness at the passing of the fertile prime of life. These feelings may even outweigh the physical discomfort caused by complex hormonal changes. Menopausal women may also experiences psychological problems like anxiety, depression, anger, fear, loss of memory and lack of concentration. Depression is found to be the most common health problem. It accounts 55\% and 36\% of women suffer from insomnia, 30\% experience forgetfulness during menopause. ${ }^{4}$ 
Menopausal changes considerably depend on the makeup of an individual and on her previous outlook at menopause and its significance. Many women in the developing countries do not know that they can age gracefully unaware of the havoc menopause can cause to their lives. Most of they suffer in silence not bringing to notice their symptoms. ${ }^{5}$

\section{STATEMENT OF THE PROBLEM}

"A study to assess the effectiveness of structure teaching programme on knowledge regarding menopausal symptoms and its management among women in the selected rural area of vadodara district."

\section{OBJECTIVES OF STUDY}

1. To assess the existing knowledge regarding Menopausal symptoms and itsmanagement among women.

2. To determine the effectiveness of structure teaching programme on Menopausal symptoms and its management among women.

3. To find out the association between post-test knowledge scores and selected demographic variable like age, education, occupation and family type.

\section{HYPOTHESES}

H1: There will be significant difference between post-test score compare to pre-test score knowledge regarding menopausal symptoms and its management.

$\mathbf{H}_{2}$ : There will be significance association between post-test knowledge of client regarding menopausal symptoms and its management and selected demographic variable.

\section{MATERIALS AND METHODS}

Research Approach: Pre experimental approach was used.

Research Design: A one group pre-test post-test design was adopted

\section{Setting of the Study:}

The study was conducted in two selected rural area of Vadodara district.

\section{Target Population:}

In the present study, the target populations were menopausal women between age group of 40-55 years.

\section{Sample:}

A total of 60 menopausal women from selected rural area of Vadodara formed the sample for the study.

\section{Sampling technique:}

Non-probability convenience sampling technique was used to select the sample for this study.

\section{Development of tool for data collection:}

The final data collection instrument had two sections which included-

Section A - Demographic Variable

Section B - Knowledge Questionnaire

\section{Validity of instrument:}

The content validity of the tools was obtained from various experts of concerned field like medicine, nursing, research and statistics.

\section{Reliability:}

Reliability of the tool was tested by split half technique (Spearman's Brown prophecy) where $r=0.90$ was found.

A pilot study was conducted with six menopausal women to refine the methodology and to find the 
feasibility of the study.

Development of structured teachingprogramme:

The following steps were adopted to develop to the structured teaching programme.

- Preparation of the structured teaching programme

- Plan for teaching

- Plan for the implementation of the structured teaching programme

\section{Data collection procedure:}

Data collection for the study was conducted at the selected rural area of Vadodara where the feasibility of conducting study was ensured after a written permission was obtained from the villages authority/ sarpanch for undertaking the study.

Informed consent was also taken from the participants. The socio demographic data and knowledge on menopausal symptoms and its management, of the participants were collected by using close ended questionnaire. Data was collected of 60 menopausal women. Immediately after pre-test, structured teaching Programme on menopausal symptoms and its management were administered to the participants with the help of charts and flash cards as audio-visual aids. Evaluation of the Structured Teaching Programme was to be done by conducting post-test, 7 days after the implementation of Structured Teaching Programme.

\section{RESULTS}

The data collected from the respondents were analysed by using descriptive and inferential statistics.

\section{Demographic characteristics}

Most of (35)percent respondents belongs to the age group of 52-56 years. Majority of the participants were married (68\%) and only $32 \%$ were widowed. $38.3 \%$ of the sample had secondary level education and $36.7 \%$ of respondents have primary level education .Data revealed $76.7 \%$ are housewife through while $13.3 \%$ are self-employed. Majority of the samples $(56.7 \%)$ have income of $>5000,35$ percent respondent have $4000-5000$, only 8.3 percent have income of 3000-4000. The majority family are joint family (65\%) and 35\% family are nuclear. (61.7) percent of the women's last child's age is more then 20 years, 25 percent of the women's last child's age is 15-20 years and only 13.3 percent of the women's last child's age is 10-15 years. The findings related to previous knowledge about menopausal symptoms and it's management was $100 \%$ women had not received any information / previous knowledge regarding menopausal symptoms and it's management.

\section{Knowledge}

Pre-test assessment revealed that the mean percentage pre-test scores were $33.27 \%$ in knowledge regarding menopausal symptoms and its management. Scores interpretation showed $63.3 \%$ of the sample with inadequate knowledge and 36,7\% with moderately adequate knowledge on menopausal symptoms and its management. Area wise assessment of knowledge depicted the component of "Symptoms of menopause" as the lowest with $30.5 \%$ mean percentage score.

Table 1: Determination of Pre Test Level Of Knowledge

\begin{tabular}{|c|c|c|c|}
\hline Level of knowledge & Score Range & Percentage Range & Pretest \\
\hline Inadequate & $0-7$ & $0-33$ & 38 \\
& & & $(63.3 \%)$ \\
\hline Moderately adequate & $8-15$ & $34-66$ & 22 \\
& & & $(36.7 \%)$ \\
\hline Adequate & $16-22$ & $67-100$ & 0 \\
\hline
\end{tabular}

Post-test assessment exhibited mean percentage post-test score of $79.40 \%$ in knowledge on menopausal symptoms and its management.Scores interpretation showed $96.67 \%$ of the sample with adequate knowledge and only $3.33 \%$ with moderately adequate knowledge. Area wise assessment of knowledge depicted the component of "Concept of menopause" as the highest with $87.75 \%$ mean percentage score. 


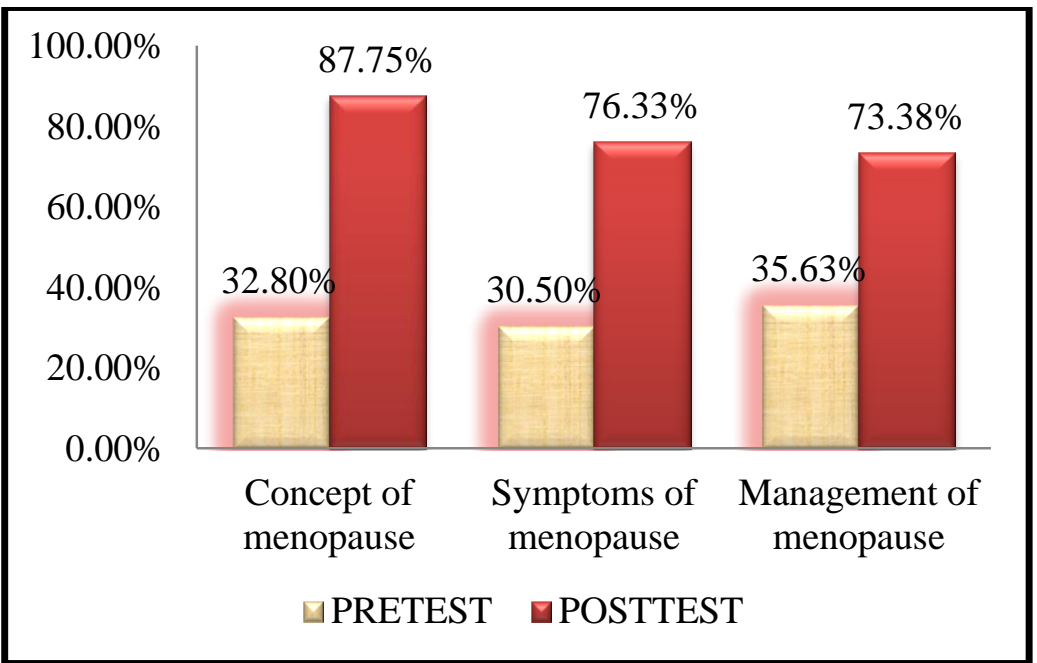

Figure 1: Comparison of Area Wise Distributions Of The Pre-test and Post-test Knowledge Scores.

\section{Effectiveness of structured teaching programme}

Further effectiveness of structured teaching programme was tested by inferential statistics using paired ' $t$ ' test. The difference between pre-test and post-test knowledge scores of menopausal women on menopausal symptoms and its effectiveness was found to be very highly significant with mean percentage knowledge score difference of $46.13 \%(t=30.83, p=0.00<0.05)$

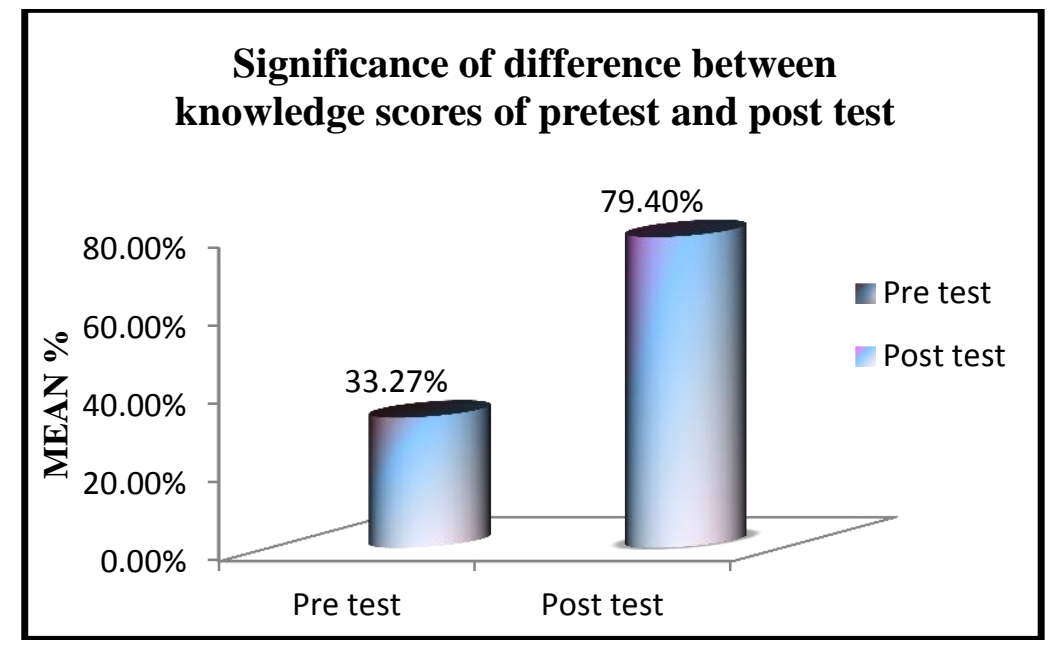

Figure 2: Overall Mean percentage distribution of pre-test and post-test scores

Association between the pre test scores of knowledge with the selected demographic variables.

Pretest knowledge score of menopausal women with their socio demographic variable the ANOVA test was done and result of study reveals that there is no any significant association of any demographic variable with posttest knowledge scores of respondents.

\section{DISCUSSION}

The finding of the studywas found similar to a study conducted by Jiny James; a study to evaluate the effectiveness of structured teaching programme on knowledge regarding menopausal problems and its remedial measures among middle aged women in selected rural areas, Bangalore. She observed that in the pre test, about $71.7 \%$ of the samples had inadequate knowledge, whereas in the post test of the samples $68.3 \%$ had gained adequate knowledge. ${ }^{6}$

\section{CONCLUSION}

Most of the women knowledge was not up to the mark before administration of structured teaching programme. This facilitated them to learn more about the menopausal symptoms and its management, the rationale behind the change and to adapt to the set of changes. The clarity of concept, symptoms and prompt management were revealed by the post-test knowledge scores. 


\section{Recommendations}

Based on the findings of the present study recommendations offered for the future

Studies are:

1. A qualitative study can be conducted regarding the symptoms experienced bymenopausal women.

2. A study to develop a standardized health assessment tool to elicit menopausalproblems among women.

3. A Self-instructional module can be developed regarding the remedial measuresof menopausal problems.

4. Menopausal symptoms can be compared with hormone replacement therapy (HRT) users and non users.

5. Longitudinal survey can be carried out to measure the hormonal changes.

6. Similar study can be conducted on a larger sample to generalize finding.

7. A comparative study can be conducted with control group.

8. The comparative study may be conducted to find out the effectiveness betweenSIM and STP regarding the same topic.

\section{Acknowledgement}

The authors acknowledge all the authorities/ sarpanch and the participants of the selected rural area of Vadodara for all their co-operation in the study.

\section{Conflict of interest:}

The authors had no relationship/condition/circumstances that present a potential conflict of interest.

Source of funding:

The authors did not receive any financial support from any third party related to the submitted work.

Ethical clearance:

The ethical clearance had been obtained from the ethical committee.

\section{References}

[1]. Dewhurst. Text book of obstetrics and gynecology for post graduates. 6th ed. Blackwel Science; 1999. p. 441-461.

[2]. Jish K. The menopausal symptom experience in young midwife women with breast cancer. Cancer Nursing 2009; 24(3): 2-1-11.

[3]. Shaws. Text book of gynecology. 11 thed. New Delhi: BI Churchill Livingstone;1998. p. 53-58.

[4]. Studd JW, Barbar R. Text book of clinical obstetrics and gynecology. 1st ed.London: Churchill Livingstone; 2007. p. $340-348$.

[5]. Meir,Stinier. Psychological aspects of post menopausal syndrome. British MedicalJournal 1999; 5:173-7.

[6]. Jiny James; a study to evaluate the effectiveness of structured teaching programme on knowledge regarding menopausal problems and its remedial measures among middle aged women in selected rural areas, Bangalore.http://hdl.handle.net/123456789/8045 